\title{
Assessment of inflammatory markers, disease severity and comorbidities in very elderly patients with acute respiratory diseases
}

\author{
Armagan Hazar, Baran Gundogus
}

Department of Pulmonary Disease, Sureyyapasa Chest Disease and Thoracic Surgery, Training and Research Hospital, Health Sciences University, Istanbul, Turkey

Submitted: 6 February 2020

Accepted: 15 March 2020

Arch Med Sci

DOI: https://doi.org/10.5114/aoms.2020.94495

Copyright @ 2020 Termedia \& Banach

\section{Abstract}

Introduction: The study aimed to evaluate the potential role of inflammatory markers (neutrophil to lymphocyte ratio (NLR), platelet to lymphocyte ratio (PLR), platelet to mean platelet volume (PLT/MPV), C-reactive protein (CRP), CRP/albumin) and demographic, clinical and laboratory parameters in predicting mortality in elderly patients.

Material and methods: A total of 1971 very elderly (age $\geq 80$ years) patients hospitalized due to acute respiratory diseases were included in this retrospective cohort study. Data on patients' demographics, reasons for admission, comorbidities, inflammatory markers on admission, hospitalization unit, length of hospital stay and survivorship status were recorded. A receiver operating characteristics (ROC) curve was plotted to determine performance of inflammatory marker levels for mortality risk. Logistic regression analysis for hospital mortality was used.

Results: A total of 1971 patients were admitted, in-ward $(n=1470)$, intensive care unit (ICU, $n=352$ ), or palliative care unit (PCU, $n=149)$, and mortality rates were $12.7 \%(n=250), 4.5 \%(n=66), 34.9 \%(n=123), 40.9 \%$ $(n=61)$ respectively. ROC analysis for area under curve (AUC) revealed significant cut-off levels for hospital mortality NLR $\geq 7.75$ ( $A U C=0.79$ ), $C R P \geq 44$ (AUC = 0.82); CRP/albumin $\geq 13.5(A U C=0.84)$ each $p<0.001$. For ICU mortality, the cut-off values and AUC were significant respectively for $\mathrm{NLR} \geq 7.75$ (AUC $=0.82), \mathrm{CRP} \geq 60$ (AUC = 0.82), APACHE II $\geq 24$ (AUC = $0.76), \mathrm{CRP} /$ albumin $\geq 26(\mathrm{AUC}=0.78), \mathrm{PLT} / \mathrm{MPV}<26.2(\mathrm{AUC}=0.31)($ each $p<0.001$ ). Binary logistic regression revealed that age above 90, PCU and ICU admission, acute and chronic renal failure and NLR $\geq 7.75$ were significant mortality predictors (odds ratio, $95 \% \mathrm{Cl}, p$-value: $2.57,1.05-6.31$, $0.039 ; 77.18,18.98-313.81<0.001 ; 20.75,1.96-98.73,<0.001 ; 18.99$, $1.31-275.31,0.031 ; 3.35,1.06-10.54,0.039 ; 7.83,3.34-18.38,0.001)$.

Conclusions: Very elderly patients with respiratory diseases who are admitted to the ICU or PCU with acute and chronic renal failure requiring ICU admission and with NLR values above 7.75 on admission have very high risk for mortality.

Key words: inflammatory markers, albumin, In hospital mortality, intensive care unit, very elderly.

\section{Introduction}

Owing to significant improvements in healthcare allowing a longer life expectancy, the number of very elderly persons ( $\geq 80$ years old) is rising

\author{
Corresponding author: \\ Armagan Hazar MD \\ Department of \\ Pulmonary Disease \\ Sureyyapasa Chest \\ Disease and \\ Thoracic Surgery \\ Training and \\ Research Hospital \\ Health Sciences University \\ Istanbul, Turkey \\ Phone: +90 05323667490 \\ E-mail: armaganhazar@ \\ yahoo.com
}


worldwide, with an estimated three-fold increase from 2015 (126.5 million) to 2050 (446.6 million) [1-3].

Alongside a vulnerability to disability and illness, the very elderly population is known to have a high prevalence of chronic diseases, multi-morbidity, frequent hospital admissions and high in-hospital mortality rates [4-6]. This emphasizes the critical importance of estimating the risk of in-hospital mortality in managing very elderly hospitalized patients in terms of clinical decision-making in identifying individuals appropriate for palliative care or targeted interventions or treatments along with the risks and benefits of potential treatments $[4,5,7,8]$.

Alongside C-reactive protein (CRP) level, neutrophil to lymphocyte ratio (NLR) and platelet to lymphocyte ratio (PLR) and platelet (PLT) indices (i.e. mean platelet volume (MPV) and PLT/MPV ratio) have recently emerged as inexpensive and readily available new potential thrombo-inflammatory markers and predictors of major adverse outcomes and mortality in various cerebrovascular and cardiovascular diseases [9-11]. However, limited data are available on the potential utility of these inflammatory indices as markers for adverse clinical outcomes, particularly in terms of in-hospital mortality risk, in the very elderly population $[3,5,8,12]$.
This study was therefore designed to evaluate the potential role of inflammatory markers (NLR, PLR, PLT/MPV, CRP and CRP/albumin) as well as demographic, clinical and laboratory parameters in predicting mortality risk among very elderly hospitalized patients.

\section{Material and methods}

\section{Study population}

Of the total of 32,238 patients hospitalized between January 2016 and October 2017 at our hospital, 2433 very elderly (aged $\geq 80$ years) patients hospitalized due to acute respiratory conditions were included in this retrospective cross sectional study. Patients hospitalized between 2016 and 2017 who were over 80 years of age at the time of hospital admission and who had complete blood count $(\mathrm{CBC})$ records at the time of hospital admission were included in the study. Patients aged $<80$ years and those without available CBC records were excluded from the study. Accordingly, 2436 out of 1971 enrolled patients were subjected to the final analysis with exclusion of 3 patients who died within the first couple of hours of emergency admission and thus had no available CBC records on the day of admission ( $n=437)$, hematologic malignancy $(n=15)$, under chemotherapy $(n=13)$ (Figure 1$)$.

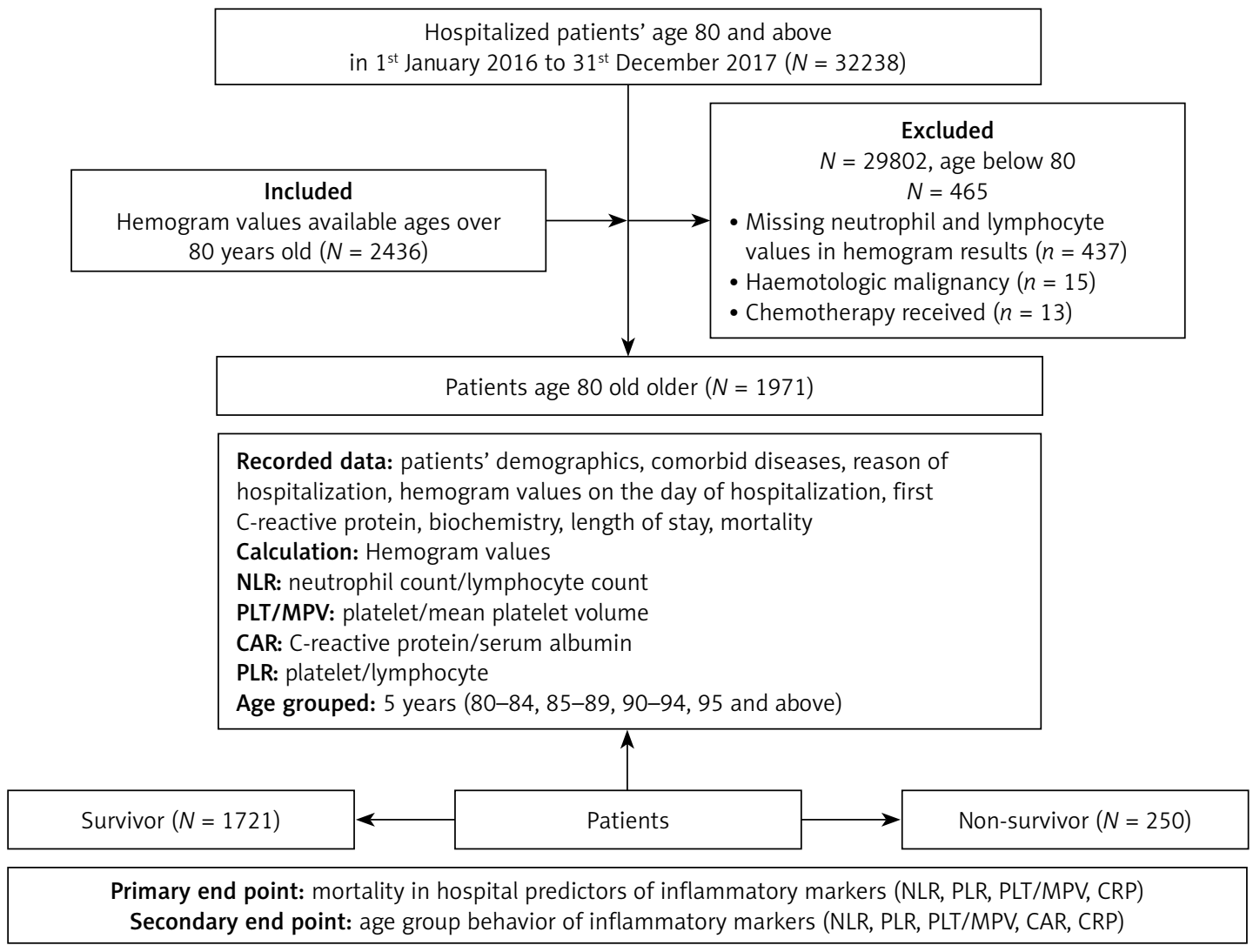

Figure 1. Study flow chart 
The study was approved by University of Health Sciences Sureyyapasa Chest Diseases and Thoracic Surgery Training and Research Hospital Scientific Research Committee on the date 12.07.2018, number 044, and it was conducted in full accordance with local Good Clinical Practice guidelines and current legislations, in accordance with the ethical principles stated in the Declaration of Helsinki. Due to the retrospective nature of the study, patient's signed informed consent was not required by the Scientific Research Committee.

\section{Study parameters}

Data on patient demographics, co-morbid diseases (diabetes, hypertension, asthma, chronic obstructive pulmonary diseases (COPD), atrial fibrillation, congestive heart failure, Alzheimer, cerebrovascular sequela, gastrostomy feeding, having tracheostomy, interstitial lung disease, lung cancer, bronchiectasis, chronic renal failure) and hospitalization unit (ward, intensive care unit (ICU), palliative care unit (PCU)), pulmonary disease related reasons for hospitalization (pneumonia, sepsis, pulmonary emboli, pleurisy, tuberculosis, malnourishment, renal failure), length of hospital stay (LOS, day), ICU severity score as Acute Physiologic And Chronic Health Evaluation (APACHE) II scores, mortality, and laboratory findings including complete blood count, inflammatory markers (NLR, PLR, PLT/MPV ratio, CRP and CRP/ albumin ratio) and blood biochemistry findings were obtained from the hospital electronic medical record system. Study variables were evaluated with respect to hospitalization unit and survivorship status.

\section{Inflammatory markers}

CBC counts including total leukocyte, neutrophil, eosinophil, lymphocyte, platelet counts, and MPV were determined using a Coulter LH 780 Hematology Analyzer (Beckman Coulter, Atlanta, GA, USA). CRP was determined using the nephelometry method BN II System (Siemens, Munich, Germany). NLR was calculated as total neutrophil count divided by total lymphocyte count. PLR was calculated as PLT count divided by total lymphocyte count. CRP to albumin ratio was calculated as serum CRP level $(\mathrm{mg} / \mathrm{l})$ divided by serum albumin level $(g / d l)$.

\section{Statistical analysis}

Statistical analysis was performed using IBM SPSS Statistics for Windows, version 20.0 (IBM Corp., Armonk, NY). Data were expressed as "mean (standard deviation; SD)", percent (\%) and median (25-75\%) where appropriate. The $\chi^{2}$ test was used to analyze categorical data, while the
Table I. Age 80 and above patients' characteristics and reason for hospitalization and hospital outcome

\begin{tabular}{|c|c|}
\hline Parameter & $N(\%)$ or mean (SD) \\
\hline Patients, $n(\%)$ & $1971(100)$ \\
\hline Age, mean (SD) [years] & $84(4)$ \\
\hline Male gender, $n(\%)$ & $1021(51.8)$ \\
\hline \multicolumn{2}{|l|}{ Age groups, $n(\%)$ : } \\
\hline $80-84$ & $978(49.6)$ \\
\hline $85-89$ & $716(36.3)$ \\
\hline $90-94$ & $226(11.5)$ \\
\hline 95 and over & $51(2.6)$ \\
\hline \multicolumn{2}{|l|}{ Admitted place: } \\
\hline Ward & $1470(74.6)$ \\
\hline Intensive Care Unit & 352 17.9) \\
\hline Palliative Care Unit & $149(7.6)$ \\
\hline \multicolumn{2}{|l|}{ Comorbid diseases: } \\
\hline COPD & $1370(69.5)$ \\
\hline Asthma & $50(2.5)$ \\
\hline Hypertension & $884(44.9)$ \\
\hline Coronary heart disease & $279(14.2)$ \\
\hline Diabetes mellitus & $370(18.8)$ \\
\hline Atrial fibrillation & $373(18.9)$ \\
\hline Congestive heart failure & $346(17.6)$ \\
\hline Alzheimer & $260(13.2)$ \\
\hline Stroke & $115(5.8)$ \\
\hline Gastrostomy tube feeding & $37(1.9)$ \\
\hline Tracheostomies & $30(1.5)$ \\
\hline Interstitial lung diseases & $114(5.8)$ \\
\hline Lung cancer & $248(12.6)$ \\
\hline Bronchiectasis & $227811.5)$ \\
\hline Chronic renal failure & $116(5.6)$ \\
\hline \multicolumn{2}{|l|}{ Reasons for hospitalization: } \\
\hline Pneumonia & $628(31.9)$ \\
\hline Pulmonary emboli & $110(5.6)$ \\
\hline Pneumothorax & $22(1.1)$ \\
\hline Pleurisy & $235(11.9)$ \\
\hline Pulmonary tuberculosis & $36(1.8)$ \\
\hline Pulmonary sepsis & $125(6.3)$ \\
\hline Acute renal failure & $73(3.7)$ \\
\hline Malnourishment & $142(7.2)$ \\
\hline $\begin{array}{l}\text { Acute on chronic respiratory } \\
\text { failure }\end{array}$ & $763(38.7)$ \\
\hline $\begin{array}{l}\text { Length of hospital stay, median } \\
(25-75 \%) \text { [days] }\end{array}$ & $6(3-8)$ \\
\hline Hospital mortality, $n$ (\%) & $250(12.7)$ \\
\hline
\end{tabular}

diseases. 
Mann-Whitney $U$ test was used for analysis of numerical data. Three groups comparisons were done by ANOVA or Kruskal-Wallis test according to dispersion. $P<0.05$ was considered statistically significant. A receiver operating characteristics (ROC) curve was plotted to determine performance (sensitivity, specificity) of inflammatory marker levels in identification of in-hospital mortality risk with calculation of AUC values and ideal cut-off value. Multivariate logistic regression was performed to determine factors predicting in-hospital mortality risk. $P<0.05$ was considered statistically significant.

\section{Results}

\section{Demographic and clinical characteristics}

Overall, mean \pm SD age was $84 \pm 4$ years and males composed $51.8 .0 \%$ of the study population. Age was stratified according to 5-year in tervals and age of half of patients was above 85 . The major first three reasons of hospitalization were acute on chronic respiratory failure, pneumonia and pleurisy. Median LOS was 6.0 days and in-hospital mortality rate was $12.7 \%(n=250)$ (Table I).

All studied inflammatory markers showed significant difference between hospitalization units (Table II)

Gender, hospitalization unit, reasons for admission and comorbidities according to survivorship status

No significant gender influence was noted on survivorship status, while survivorship status differed significantly with respect to hospital unit with higher likelihood of in-hospital mortality in elderly patients hospitalized in palliative care (40.9\%) (Table III).

\section{Inflammatory markers and blood biochemistry findings according to survivorship status}

Mean patient age and median values for CRP, NLR and CRP/albumin ratio and PLR were significantly higher, whereas PLT/MPV was significantly lower in non-survivors than in survivors ( $p<0.001$ for each) (Table IV). Blood biochemistry findings revealed significantly higher serum values for glucose, urea, creatinine, lactate dehydrogenase $(\mathrm{LDH})$, serum glutamic oxaloacetic transaminase (SGOT) and serum glutamic pyruvic transaminase (SGPT) along with significantly lower values for protein and albumin among non-survivors compared to survivors ( $p<0.001$ for each) (Table IV).

The inflammatory markers are compared according to mortality in the place of admittance to hospital in Table V. The median CRP values were significantly higher in the ward than the PCU and the median NLR values were also significantly higher in the ward than the ICU and PCU in non-survivors than survivors. In the ICU, APACHE II score and CRP/albumin were significantly higher and PLT/MPV, platelet and albumin were lower in non-survivors (Table $\mathrm{V}$ ).

ROC analysis for performance of inflammatory markers in identification of mortality risk in hospital revealed that NLR, PLT/MPV, CRP/albumin ratio, and CRP levels with cut-off values were potential markers of in-hospital mortality risk in very elderly hospitalized patients (Figure 2).

ROC analysis for performance of inflammatory markers in identification of mortality risk in the ICU revealed that APACHE II score, NLR, PLT/MPV $\mathrm{CRP} /$ albumin ratio, and CRP levels with cut-off values were potential markers of in-hospital mortality risk in very elderly patients in the ICU (Figure 3 ).

Binary logistic regression analysis was done and age above 90, CRP $=44$ and above, CRP/al-

Table II. Inflammatory markers according to hospitalization place

\begin{tabular}{|c|c|c|c|c|c|c|c|}
\hline \multirow[t]{3}{*}{ Parameter } & \multicolumn{6}{|c|}{ Location } & \multirow[t]{3}{*}{$P$-value } \\
\hline & \multicolumn{2}{|r|}{$\begin{array}{c}\text { Ward (a) } \\
(N=1470)\end{array}$} & \multicolumn{2}{|r|}{$\begin{array}{c}\text { ICU (b) } \\
(N=352)\end{array}$} & \multicolumn{2}{|c|}{$\begin{array}{l}\text { Palliative care (c) } \\
\qquad(N=149)\end{array}$} & \\
\hline & $N$ & Median & $N$ & Median & $N$ & Median & \\
\hline NLR & 1470 & $5.96(3.53-11.0)$ & 352 & $7.81(4.35-16.86)$ & 149 & $8.33(3.91-22.00)$ & $<0.001$ \\
\hline $\mathrm{CRP}^{*}$ & 1342 & $20.1(7.7-52.1)$ & 313 & $60.7(24.2-133.0)$ & 91 & $67.1(26.0-125.0)$ & $<0.001$ \\
\hline CAR $^{\#}$ & 558 & $6.71(2.20-17.24)$ & 126 & $26.61(8.06-61.57)$ & 36 & $25.28(9.55-47.07)$ & $<0.001$ \\
\hline PLR & 1469 & $\begin{array}{c}216.67 \\
(147.50-325.0)\end{array}$ & 351 & $\begin{array}{c}190.00 \\
(121.25-324.00) \\
\end{array}$ & 149 & $\begin{array}{c}258.75 \\
(144.09-420.00) \\
\end{array}$ & $<0.001$ \\
\hline PLTMPV & 1469 & $\begin{array}{c}28.76 \\
(20.99-38.99)\end{array}$ & 352 & $\begin{array}{c}23.79 \\
(14.48-32.69)\end{array}$ & 149 & $\begin{array}{c}26.13 \\
(17.82-35.12)\end{array}$ & $<0.001$ \\
\hline
\end{tabular}

${ }^{*} C$-reactive protein was absent in 225 patients. ${ }^{*}$ Albumin was absent in 128 patients. NLR - neutrophil count/lymphocyte count, PLT/MPV platelet/mean platelet volume, CAR - C-reactive protein/serum albumin, PLR-platelet/lymphocyte. Groups' comparison by nonparametric Kruskal-Wallis test. 
Table III. Gender, hospitalization unit and diagnosis according to survivor status

\begin{tabular}{|c|c|c|c|}
\hline Parameter & Survivor $(N=1721)$ & Non-survivor $(N=250)$ & $P$-value \\
\hline Gender male, $n$ (column \%) & $885(51.4)$ & $136(54.4)$ & 0.38 \\
\hline \multicolumn{4}{|l|}{ Age group, $n$ (row \%): } \\
\hline $80-84$ & $872(89.2)$ & $106(10.8)$ & \multirow[t]{4}{*}{0.001} \\
\hline $85-89$ & $626(87.4)$ & $90(12.6)$ & \\
\hline $90-94$ & $184(81.4)$ & $42(18.6)$ & \\
\hline 95 and above & $39(76.5)$ & $12(23.5)$ & \\
\hline \multicolumn{4}{|l|}{ Hospitalization unit, $n$ (row \%): } \\
\hline Ward & $1404(95.5)$ & $66(4.5)$ & \multirow[t]{3}{*}{$<0.001$} \\
\hline Intensive care unit & $229(65.1)$ & $123(34.9)$ & \\
\hline Palliative care unit & $88(59.1)$ & $61(40.9)$ & \\
\hline \multicolumn{4}{|l|}{ Comorbid diagnoses* $^{*} n(\%):$} \\
\hline Chronic obstructive pulmonary diseases & $1232(71.6)$ & $138(55.2)$ & $<0.001$ \\
\hline Hypertension & $778(45.2)$ & $106(42.4)$ & 0.40 \\
\hline Alzheimer & $196(11.4)$ & $64(25.6)$ & $<0.001$ \\
\hline Coronary artery disease & $256(14.9)$ & $23(9.2)$ & 0.016 \\
\hline Atrial fibrillation & $332(19.3)$ & $41(16.4)$ & 0.28 \\
\hline Chronic kidney disease & $86(5.0)$ & $30(12.0)$ & $<0.001$ \\
\hline Stroke & $90(5.2)$ & $25(10.0)$ & 0.003 \\
\hline Diabetes & $326(18.9)$ & $44(17.6)$ & 0.61 \\
\hline Tracheostomy & $27(1.6)$ & $3(1.2)$ & 0.66 \\
\hline Gastrostomy tube feeding & $31(1.8)$ & $6(2.4)$ & 0.52 \\
\hline Congestive heart failure & $303(17.6)$ & $43(17.2)$ & 0.88 \\
\hline Chronic respiratory failure & $622(16.6)$ & $141(14.0)$ & 0.30 \\
\hline \multicolumn{4}{|l|}{ Acute conditions, $n(\%)$ : } \\
\hline $\begin{array}{l}\text { Exacerbation of chronic obstructive } \\
\text { diseases }\end{array}$ & $525(30.5)$ & $76(30.4)$ & 0.97 \\
\hline Nutritional disorder & $89(5.2)$ & $53(21.2)$ & $<0.001$ \\
\hline Pleural effusion & $207(12.0)$ & $28(11.2)$ & 0.71 \\
\hline Acute respiratory failure & $622(36.1)$ & $141(56.4)$ & $<0.001$ \\
\hline Lung malignancy & $206(12.0)$ & $42(16.8)$ & 0.031 \\
\hline Other malignancies & $87(5.1)$ & $19(7.6)$ & 0.10 \\
\hline Pulmonary embolism & $99(5.8)$ & $11(4.4)$ & 0.38 \\
\hline Bronchiectasis & $177(10.3)$ & $50(20.0)$ & $<0.001$ \\
\hline Pneumonia & $493(28.6)$ & $135(54.0)$ & $<0.001$ \\
\hline Myocardial infarction & $321(18.7)$ & $43(17.2)$ & 0.58 \\
\hline Pneumothorax & $20(1.2)$ & $2(0.8)$ & $>0.99$ \\
\hline Tuberculosis & $31(1.8)$ & $5(2.0)$ & 0.83 \\
\hline Acute kidney failure & $41(2.4)$ & $32(12.8)$ & $<0.001$ \\
\hline Sepsis & $58(3.4)$ & $67(26.8)$ & $<0.001$ \\
\hline Interstitial lung disease & $90(5.2)$ & $24(9.6)$ & 0.006 \\
\hline Asthma attack & $46(2.7)$ & $4(1.6)$ & 0.39 \\
\hline
\end{tabular}

COPD - chronic obstructive pulmonary disease. "More than one diagnosis might be present in some patients. $\chi^{2}$ test, ${ }^{*}$ Fisher's exact test. 
Table IV. Patient age and inflammatory markers and blood biochemistry findings according to survivorship status

\begin{tabular}{|c|c|c|c|c|c|}
\hline \multirow[t]{2}{*}{ Parameter } & \multicolumn{2}{|c|}{ Survivor $(N=1721)$} & \multicolumn{2}{|c|}{ Non-survivor $(N=250)$} & \multirow[t]{2}{*}{$P$-value } \\
\hline & $N$ & Values & $N$ & Values & \\
\hline Age, mean (SD) [year] & 1721 & $85(4)$ & 250 & $86(5)$ & $<0.001$ \\
\hline WBC count $\left[\times 10^{3} / \mu \mathrm{l}\right]$ & 1721 & $8.9(6.9-11.7)$ & 250 & $14.5(9.4-20.4)$ & $<0.001$ \\
\hline Neutrophil, \% & 1721 & $76.9(68.2-85.0)$ & 250 & $90.3(84.4-94.3)$ & $<0.001$ \\
\hline Lymphocyte, \% & 1721 & $13.4(8.2-19.9)$ & 250 & $4.5(2.7-9.5)$ & $<0.001$ \\
\hline Platelet count $\left[\times 10^{3} / \mu \mathrm{l}\right]$ & 1720 & $244(190-313)$ & 249 & $188(115-270)$ & $<0.001$ \\
\hline MPV [fl] & 1720 & $8.50(7.90-9.30)$ & 249 & $9.20(8.30-10.36)$ & 0.045 \\
\hline PLR $\left[\times 10^{2}\right]$ & 1720 & $211(144-322)$ & 249 & $255(128-449)$ & $<0.001$ \\
\hline NLR & 1721 & $5.73(3.40-10.30)$ & 250 & $17.52(8.89-32.80)$ & $<0.001$ \\
\hline PLT/MPV $\left[\times 10^{3}\right]$ & 1720 & $28.5(20.8-38.4)$ & 250 & $20.2(10.4-32.7)$ & $<0.001$ \\
\hline CRP/albumin ratio & 1461 & $6.85(2.48-18.10)$ & 201 & $50.00(22.15-87.62)$ & $<0.001$ \\
\hline CRP $[\mathrm{mg} / \mathrm{dl}]$ & 1534 & $21.4(8.5-53.6)$ & 212 & $112.0(53.5-173.0)$ & $<0.001$ \\
\hline \multicolumn{6}{|l|}{ Blood biochemistry: } \\
\hline Glucose [mg/dl] & 1627 & $121(97-162)$ & 242 & $136(104-182)$ & $<0.001$ \\
\hline Urea [mg/dl] & 1635 & $52(37-77)$ & 245 & $85(60-130)$ & $<0.001$ \\
\hline Creatinine $[\mathrm{mg} / \mathrm{dl}]$ & 1636 & $0.90(0.70-1.20)$ & 245 & $1.30(0.70-2.20)$ & $<0.001$ \\
\hline Albumin [g/dl] & 1608 & $3.2(2.8-3.5)$ & 235 & $2.3(2.0-2.8)$ & $<0.001$ \\
\hline Sodium [mmol] & 1610 & $139(136-142)$ & 241 & $140(135-144)$ & 0.037 \\
\hline Potassium [mmol] & 1611 & $4.2(3.8-4.6)$ & 238 & $4.2(3.5-4.9)$ & 0.55 \\
\hline Lactate dehydrogenase [U/I] & 1297 & $228(189-284)$ & 182 & $304(237-441)$ & $<0.001$ \\
\hline AST [U/I] & 1606 & $22(17-31)$ & 235 & $33(20-59)$ & $<0.001$ \\
\hline ALT $[U / I]$ & 1619 & $17(11-27)$ & 241 & $20(12-40)$ & 0.003 \\
\hline
\end{tabular}

Values median (25-75\%) if not mentioned, Mann-Whitney U test. Mean (SD) analyzed by Student's t test. WBC - white blood cells, CRP $C$-reactive protein, NLR - neutrophil to lymphocyte ratio, PLR - platelet to lymphocyte ratio, PLTIMPV - platelet to mean platelet volume, AST - aspartate transaminase, ALT - alanine transaminase.

bumin $=13.5$ and above, PLT/MPV $=26.2 \times 10^{3}$, $\mathrm{NLR}=7.75$ and above patients, hospitalization place, comorbid diseases (chronic renal failure, Alzheimer, interstitial lung diseases) reasons for hospitalization (acute respiratory failure, pneumonia, acute renal failure, malnourishment, sepsis, exacerbation of chronic obstructive pulmonary diseases) were included in the model for determining the risk of hospital mortality. Considering laboratory parameters, NLR over 7.75 (OR $=7.83$, $p<0.001)$ was only determined to significantly predict an increased in-hospital mortality risk among very elderly patients (Table VI).

\section{Discussion}

This study findings in a retrospective cohort of very elderly (age 80 and above) patients hospitalized due to respiratory diseases revealed that the in-hospital mortality rate was $12.7 \%$ and among inflammatory markers, ROC analysis of AUC showed the cut-off values of mortality in hospital for CRP above $44 \mathrm{mg} / \mathrm{dl}$, CRP/albumin values above 13.5; NLR values above 7.75 and PLT/MPV values below 26.2. ROC analysis of AUC showed the cut-off values of mortality in elderly patients who require ICU, APACHE II values above 24, CRP values above $60 \mathrm{mg} / \mathrm{dl}$, CRP/albumin above 26, NLR and PLT/MPV values the same as hospital mortality cut-off values. The study found that increased risk of in-hospital mortality in cases of acute and chronic renal failure, requiring ICU and palliative care unit admission, and NLR equal to 7.75 and above were significant predictors of increased risk of mortality in very elderly hospitalized patients.

Pneumonia, sepsis, bronchiectasis, acute renal failure and lung cancer at admission or co-morbid chronic renal diseases and nutritional problems, 
Table V. Comparison of patients' mortality groups with inflammatory markers according to hospitalization place

\begin{tabular}{|c|c|c|c|c|c|}
\hline \multirow[t]{2}{*}{ Parameter } & \multicolumn{2}{|r|}{ Survivor } & \multicolumn{2}{|r|}{ Non-survivor } & \multirow[t]{2}{*}{$P$-values } \\
\hline & $N$ & Values & $N$ & Values & \\
\hline \multicolumn{6}{|l|}{ Ward: } \\
\hline $\mathrm{CRP}[\mathrm{mg} / \mathrm{dl}]$ & 1342 & $8.2(4.0-21.6)$ & 65 & $17.2(8.2-42.3)$ & $<0.001$ \\
\hline Albumin [mg/dl] & 1334 & $3.3(2.9-3.6)$ & 65 & $2.6(2.3-3.1)$ & $<0.001$ \\
\hline CRP/albumin & 1230 & $6.0(2.1-15.8)$ & 60 & $34.9(13.9-71.32)$ & $<0.001$ \\
\hline NLR & 1344 & $9.80(4.40-22.45)$ & 61 & $76.60(26.0-147.00)$ & $<0.001$ \\
\hline $\mathrm{PLT} / \mathrm{MPV}\left[\times 10^{3}\right]$ & 641 & $29.5(21.5-39.0)$ & 10 & $27.1(18.1-33.8)$ & 0.20 \\
\hline MPV [fl] & 1403 & $8.5(7.8-9.2)$ & 66 & $8.7(7.6-9.7)$ & 0.21 \\
\hline Platelet $\left[\times 10^{3}\right]$ & 1403 & $248(192-318)$ & 66 & $233(146-289)$ & 0.006 \\
\hline $\operatorname{PLR}\left[\times 10^{2}\right]$ & 1403 & $214(147-324)$ & 66 & $278(162-492)$ & 0.003 \\
\hline \multicolumn{6}{|l|}{ ICU: } \\
\hline $\mathrm{CRP}[\mathrm{mg} / \mathrm{dl}]$ & 216 & $10.1(4.6-30.2)$ & 121 & $28.8(11.4-81.6)$ & $<0.001$ \\
\hline Albumin [mg/dl] & 192 & $2.8(2.4-3.1)$ & 111 & $2.1(1.9-2.6)$ & $<0.001$ \\
\hline CRP/albumin & 178 & $13.0(5.4-30.6)$ & 105 & $73.5(33.3-110.8)$ & $<0.001$ \\
\hline NLR & 211 & $10.90(5.22-36.90)$ & 117 & $68.97(23.89-166.00)$ & $<0.001$ \\
\hline $\mathrm{PLT} / \mathrm{MPV}\left[\times 10^{3}\right]$ & 108 & $25.0(17.8-32.5)$ & 42 & $12.3(6.7-25.9)$ & $<0.001$ \\
\hline MPV $[\mathrm{fl}]$ & 229 & $8.8(8.1-9.6)$ & 122 & $9.6(8.7-10.6)$ & $<0.001$ \\
\hline Platelet $\left[\times 10^{3}\right]$ & 229 & $229(173-293)$ & 122 & $153(77-237)$ & $<0.001$ \\
\hline $\operatorname{PLR}\left[\times 10^{2}\right]$ & 229 & $189(131-302)$ & 122 & $193(89-348)$ & 0.71 \\
\hline APACHE II, mean (SD) & 229 & $24 \pm 2$ & 123 & $26 \pm 3$ & $<0.001$ \\
\hline \multicolumn{6}{|l|}{ Palliative care: } \\
\hline CRP $[\mathrm{mg} / \mathrm{dl}]$ & 68 & $9.6(3.6-26.1)$ & 50 & $38.9(11.2-75.3)$ & $<0.001$ \\
\hline Albumin [mg/dl] & 82 & $2.8(2.5-3.2)$ & 59 & $2.4(2.0-2.7)$ & $<0.001$ \\
\hline CRP/albumin & 53 & $20.3(7.4-40.6)$ & 36 & $33.3(11.7-62.3)$ & 0.027 \\
\hline NLR & 74 & $9.97(4.17-55.90)$ & 48 & $27.72(15.52-81.95)$ & 0.002 \\
\hline $\mathrm{PLT} / \mathrm{MPV}\left[\times 10^{3}\right]$ & 40 & $24.8(17.9-31.9)$ & 28 & $19.1(14.1-29.3)$ & 0.11 \\
\hline MPV [fl] & 88 & $8.4(7.9-9.4)$ & 61 & $8.9(7.9-9.9)$ & 0.10 \\
\hline Platelet $\left[\times 10^{3}\right]$ & 88 & $230(190-300)$ & 61 & $207(147-284)$ & 0.10 \\
\hline $\operatorname{PLR}\left[\times 10^{2}\right]$ & 88 & $210(136-323)$ & 61 & $323(222-663)$ & 0.001 \\
\hline
\end{tabular}

Values median (25-75\%) if not mentioned, Mann-Whitney $U$ test used. Mean (SD) analyzed by Student's $t$ test. CRP - C-reactive protein, $N L R$ - neutrophil to lymphocyte ratio, PLR - platelet to lymphocyte ratio, PLT/MPV - platelet to mean platelet volume.

Alzheimer's disease and stroke were also noted among non-survivors in the univariate analysis in our cohort of elderly patients. This supports the suggestion that alongside the reason for admission $[5,8]$, the prevalence, number and type of co-morbidities are also associated with increased mortality risk among very elderly patients, particularly for co-morbid hypertension, dementia and pneumonia [3, 13-17]. In the present study hypertension was the second most prevalent co-morbid disease after COPD; it was found at nearly the same rate among survivors and non-survivors.

Reasons for admission in our cohort also show that the elderly comprise a highly heterogeneous population with multi-comorbidities alongside a high risk of frailty and vulnerability to inability to cope with stressors, such as hospitalization or acute illness [18]. In the present study, the mortality rate according to admitted place of hospital revealed that palliative care admitted patients had a higher mortality rate because of various underlying terminal state diseases.

Notably, hospitalization in respiratory diseases with the diagnosis of COPD was more prevalent in survivors than in non-survivors in our cohort. This seems consistent with data from a past study from Turkey, which indicated an increase in prevalence and similarly good outcome of COPD-related hospitalizations in very elderly patients from 2008 to 2014 [12]. In addition, statistically significantly 
Table VI. Binary logistic regression analysis predictors for mortality in hospitalized elderly patients

\begin{tabular}{|c|c|c|c|c|}
\hline \multirow[t]{2}{*}{ Parameter } & \multirow[t]{2}{*}{ Odds ratio } & \multicolumn{2}{|c|}{$95 \% \mathrm{Cl}$ for $\mathrm{OR}$} & \multirow[t]{2}{*}{$P$-values } \\
\hline & & Lower & Upper & \\
\hline Age 90 and over & 2.57 & 1.05 & 6.31 & 0.039 \\
\hline \multicolumn{5}{|l|}{ Location: } \\
\hline Palliative care unit & 77.18 & 18.98 & 313.81 & $<0.001$ \\
\hline Intensive care unit & 20.75 & 7.95 & 54.12 & $<0.000$ \\
\hline \multicolumn{5}{|l|}{ Inflammatory markers: } \\
\hline NLR 7.75 and over & 7.83 & 3.34 & 18.38 & $<0.001$ \\
\hline CRP/albumin 13.50 and over & 6.88 & 0.76 & 61.98 & 0.09 \\
\hline CRP $44 \mathrm{mg} / \mathrm{dl}$ and over & 0.84 & 0.11 & 6.58 & 0.87 \\
\hline PLT/MPV 26.2 and over & 1.82 & 0.83 & 3.99 & 0.14 \\
\hline \multicolumn{5}{|l|}{ Co-morbid diseases: } \\
\hline Chronic renal failure & 3.35 & 1.06 & 10.54 & 0.039 \\
\hline Alzheimer & 1.62 & 0.70 & 3.76 & 0.26 \\
\hline Interstitial lung diseases & 2.08 & 0.69 & 6.22 & 0.19 \\
\hline \multicolumn{5}{|l|}{ Reasons of hospitalization: } \\
\hline Pneumonia & 0.65 & 0.19 & 2.16 & 0.48 \\
\hline Acute respiratory failure & 0.51 & 0.04 & 5.87 & 0.59 \\
\hline Mal nourishment & 0.43 & 0.06 & 3.25 & 0.41 \\
\hline Acute renal failure & 18.99 & 1.31 & 275.31 & 0.031 \\
\hline Sepsis & 4.53 & 0.64 & 32.21 & 0.13 \\
\hline Exacerbation of COPD & 1.01 & 0.08 & 12.48 & 0.99 \\
\hline
\end{tabular}

higher levels of CRP, CRP/albumin, and NLR in patients hospitalized at the ICU and palliative care unit than the ward in our cohort seem to be in line with the association of these two hospital units with the higher in-hospital mortality rates. The present study also evaluated the predictive power of well-known inflammatory markers such as CRP and rather new used inflammatory markers such as NLR, CRP/albumin, PLT/MPV and PLR. Unlike other studies, in our study, the multivariate analysis included these inflammatory markers beside co-morbid diseases and reason for acute hospitalization diseases in the regression model. The potential utility of CRP and NLR in identification of poor prognosis in the ICU and palliative care unit seems also notable in this regard, given the importance of making quick and accurate decisions in the care for the seriously ill or frail patients in order to prioritize those with a high risk of mortality [19].

Our ROC analysis showed that the cut-off values of mortality with higher area under curve find- ings related to the prognostic role of CRP levels $\geq 44 \mathrm{mg} / \mathrm{dl}, \mathrm{NLR} \geq 7.75$ and PLT/MPV ratio $<26.2$ $\times 10^{3}$ and CRP/albumin $\geq 13.5$ in predicting increased in-hospital mortality risk and in discriminating non-survivors in very elderly hospitalized patients, emphasizing the potential utility of these prognostic markers in helping clinical decision making to optimize the coherence between targets of care and realistic clinical outcomes alongside health care resource utilization [20]. Consistent with our findings, elevated levels of CRP were reported to be associated with increased risks of frailty, overnight hospital admission and short-term all-cause mortality in the elderly population $[14,21]$. Poredos et al. showed that increased circulating inflammatory markers in patients with superficial vein thrombosis could be a sign for presence of occlusion of veins [22]. The NLR was indicated to be an inexpensive and readily available biomarker that can help to identify individuals at risk of in-hospital complications and in-hospital mortality [10, 23]. Indeed, 


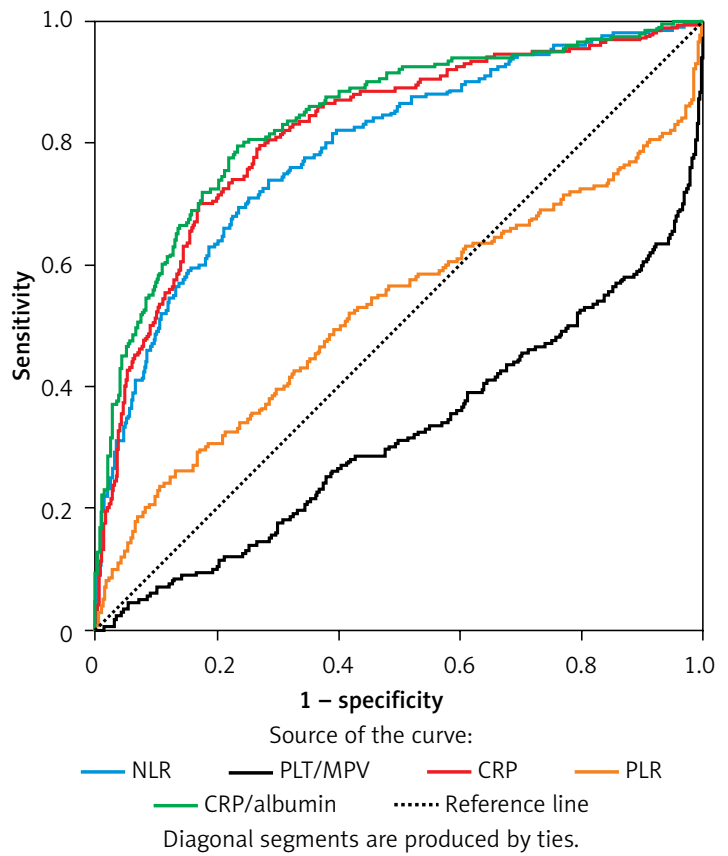

Area under the curve of inflammatory markers for mortality of hospitalized elderly patients

\begin{tabular}{|lccccccc|}
\hline Variables & Area & \multicolumn{2}{c}{$\begin{array}{c}\text { Asymptotic 95\% } \\
\text { confidence interval }\end{array}$} & P-values & Cut-off & $\begin{array}{c}\text { Sensitivity } \\
\text { (\%) }\end{array}$ & $\begin{array}{c}\text { Specificity } \\
\text { (\%) }\end{array}$ \\
\cline { 2 - 5 } Nower bound Upper bound & & & & & \\
\hline CRP & 0.79 & 0.76 & 0.83 & $<0.001$ & 7.75 & 82 & 64 \\
\hline PLT/MPV & 0.82 & 0.79 & 0.85 & $<0.001$ & 44 & 85 & 68 \\
\hline $\begin{array}{l}\text { Platelet/ } \\
\text { lymphocyte }\end{array}$ & 0.52 & 0.48 & 0.37 & $<0.001$ & 26 & 72 & 41 \\
\hline $\begin{array}{l}\text { CRP/ } \\
\text { albumin }\end{array}$ & 0.84 & 0.81 & 0.87 & 0.28 & 219 & 56 & 53 \\
\hline
\end{tabular}

Mortality positive $n=200$, negative $n=1460$, missing $n=311$. CRP - C-reactive protein, $N L R$ - neutrophil to lymphocyte ratio, $P L R$ - platelet to lymphocyte ratio, PLT/MPV - platelet to mean platelet volume.

Figure 2. ROC curve analysis for the role of inflammatory markers in discriminating non-survivors among very elderly hospitalized patients. Area under the curve for mortality in hospital for elderly patients are shown in the table

an NLR cut-off value of 5.0 was shown to predict the medium- to long-term mortality in patients with acute coronary syndrome [10], while an NLR cut-off value of 7.35 was reported to identify 30-day mortality in patients with acute intracerebral hemorrhage [24]. The lower PLT/MPV ratio in non-survivors than in survivors in our cohort seems consistent with data from a past study on predictors of in-hospital mortality in 1556 ICU patients, which indicated an association of higher MPV and lower platelet count with a higher mortality rate [11].

The established role of higher CRP and low serum albumin levels as CRP to serum albumin ratio has a crucial role for predicting increased in-hospital mortality in our cohort, which seems notable given that hypoalbuminemia has been considered to offer strong prognostic information additional to usual prognostic variables for the prediction of in-hospital mortality in elderly patients admitted for acute cardiac conditions [25-27]. Past studies also reported the association of hypoalbuminemia with mortality and severity of pneumonia in hospitalized patients with community acquired pneumonia [28] and with mortality after oncological surgery among the elderly [29, 30]. Repeated microalbuminuria testing can be used for an early predictor of development of nephropathy in patients with type 1 diabetes rather than mortality in all age groups [31].

In this regard, the potential utility of NLR, CRP and PLT/MPV ratio in prediction of in-hospital mortality risk among very elderly patients seems also important given the simplicity, low cost, and availability of these inflammatory markers with a broad prognostic range across different clinical 


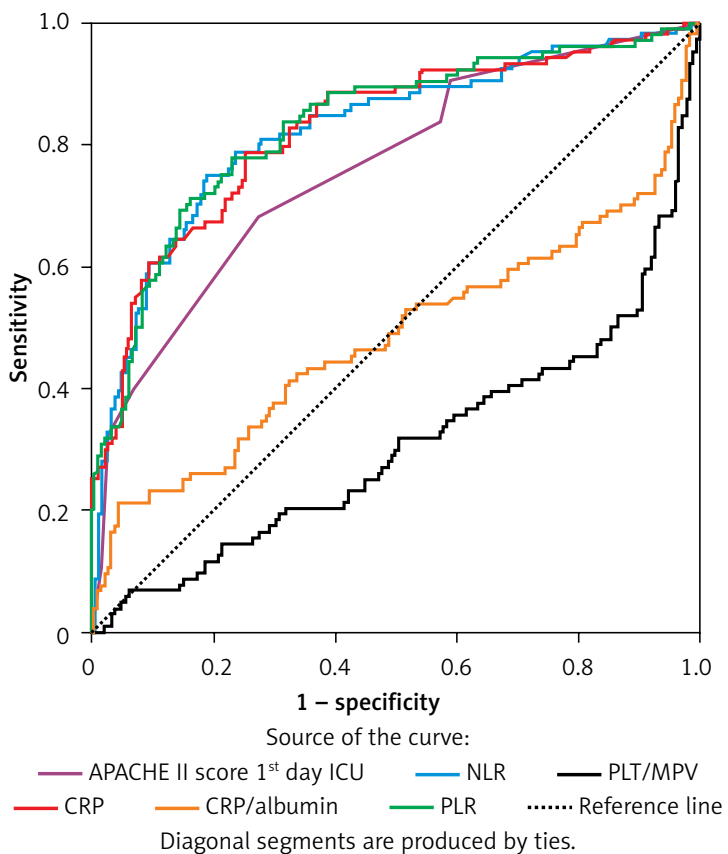

Area under the curve for mortality in Intensive Care Unit elderly patients

\begin{tabular}{|c|c|c|c|c|c|c|c|}
\hline \multirow[t]{2}{*}{ Variables } & \multirow[t]{2}{*}{ Area } & \multicolumn{2}{|c|}{$\begin{array}{l}\text { Asymptotic } 95 \% \text { confi- } \\
\text { dence interval }\end{array}$} & \multirow[t]{2}{*}{$P$-values } & \multirow[t]{2}{*}{ Cut-off } & \multirow[t]{2}{*}{$\begin{array}{c}\text { Sensitivity } \\
(\%)\end{array}$} & \multirow[t]{2}{*}{$\begin{array}{l}\text { Specificity } \\
\text { (\%) }\end{array}$} \\
\hline & & $\begin{array}{l}\text { Lower } \\
\text { bound }\end{array}$ & $\begin{array}{l}\text { Upper } \\
\text { bound }\end{array}$ & & & & \\
\hline $\begin{array}{l}\text { APACHE II score } \\
1^{\text {st }} \text { day ICU }\end{array}$ & 0.76 & 0.70 & 0.82 & $<0.001$ & 24 & 76 & 72 \\
\hline NLR & 0.82 & 0.77 & 0.88 & $<0.001$ & 7.75 & 82 & 64 \\
\hline PLT/MPV $\left[\times 10^{3}\right]$ & 0.31 & 0.24 & 0.37 & $<0.001$ & 26 & 73 & 52 \\
\hline CRP $[\mathrm{mg} / \mathrm{dl}]$ & 0.82 & 0.77 & 0.88 & $<0.001$ & 60 & 83 & 67 \\
\hline CRP/albumin & 0.83 & 0.78 & 0.88 & $<0.001$ & 26 & 83 & 68 \\
\hline $\begin{array}{l}\text { Platelet/ } \\
\text { lymphocyte }\left[\times 10^{2}\right]\end{array}$ & 0.48 & 0.41 & 0.56 & 0.62 & 192 & 48 & 51 \\
\hline
\end{tabular}

Positive case $n=104$, negative case $n=178$, missing value $n=70$. APACHE $I I-$ acute and chronic health evaluation score, $C R P-C$-reactive protein, NLR - neutrophil to lymphocyte ratio, PLR - platelet to lymphocyte ratio, PLT/MPV - platelet to mean platelet volume.

Figure 3. ROC curve analysis for the role of inflammatory markers, APACHE II in discriminating non-survivors among very elderly ICU patients. Area under the curve for mortality in Intensive Care Unit for elderly patients are shown in the table

conditions including cardiovascular disease, malignancies, and infectious diseases [10, 32, 33].

A major strength of the current study is the comprehensive assessment of potential prognostic factors related to patient demographics, admission or co-morbid diagnosis, hospital units, inflammatory markers and other laboratory findings, as well as provision of data on cut-off values of inflammatory markers for discrimination of non-survivors from survivors in a relatively high number of very elderly patients hospitalized with heterogeneous diagnoses. However, certain limitations to this study should be considered. First, due to the retrospective single center design, establishing the temporality between cause and effect as well as generalizing our findings to overall very elderly hospitalized population seems difficult. Second, given that patient outcome in the elderly is also certainly affected by the patient frailty, lack of data on patient frailty is another limitation which otherwise would extend the knowledge achieved in the current study. Nevertheless, despite these certain limitations, given the paucity of solid information available in this area, our findings represent a valuable contribution to the literature

In conclusion, our findings revealed admission for very elderly patients especially over 90 years old having chronic renal failure co-morbidities and acute renal failure due to sepsis requiring intensive care unit and palliative care unit stay as well as NLR $\geq 7.75$ significantly predict increased risk 
of in-hospital mortality among very elderly hospitalized patients. In addition, NLR $\geq 7.75$ and also CRP levels $\geq 44 \mathrm{mg} / \mathrm{dl}$, CRP/albumin $\geq 13.5$ and PLT/MPV ratio $<26.2 \times 10^{3}$ levels can be used for estimation of high risk of in-hospital mortality among very elderly hospitalized patients. Very elderly patients are expected to have high risk of in-hospital mortality, but in those patients hospital mortality is about $13 \%$. The estimation of high risk of mortality is important for the early approach and for this purpose NLR could be very helpful, like CRP/albumin and presence of renal failure. Our findings emphasize the importance of nutritional screening at hospital admission as well as the potential utility of inflammatory markers in aiding clinical decision making among very elderly hospitalized patients in terms of recognizing and predicting the prognostic outcome and identifying individuals for whom palliative care or targeted interventions and treatments are indicated.

\section{Acknowledgments}

Thanks to Head of Hospital to Associate Prof Dr. Zuhal Karakurt for data and further study analysis.

\section{Conflict of interest}

The authors declare no conflict of interest.

\section{References}

1. Lee GK, Ullery BW, Lee JT. Elective EVAR in nonagenarians is safe in carefully selected patients. Ann Vasc Surg 2014; 28: 1402-8.

2. He W, Goodkind D, Kowal PUS. Census Bureau, International Population Reports. P95/16e1, An Aging World:2015. Washington, DC: U.S. Government Publishing Office; 2016.

3. Kassahun WT, Staab H, Gockel I, Mehdorn M. Factors associated with morbidity and in-hospital mortality after surgery beyond the age of 90: comparison with outcome results of younger patients matched for treatment. Am J Surg 2018: 216: 1063-9.

4. Gallego González E, Ortiz Alonso FJ, Vidán Astiz MT, et al. Development and validation of a prognostic index for 6- and 12-month mortality in hospitalized older adults. Arch Gerontol Geriatr 2017; 73: 269-78.

5. Launay CP, Rivière H, Chabot J, et al. Prediction of in-hospital mortality with the 6-item Brief Geriatric Assessment tool: an observational prospective cohort study. Maturitas 2018; 110: 57-61.

6. Salive ME. Multimorbidity in older adults. Epidemiol Rev 2013; 35: 75-83.

7. Yourman LC, Lee SJ, Schonberg MA, et al. Prognostic indices for older adults: a systematic review. JAMA 2012; 307: 182-92.

8. Silva TJA, Jerussalmy CS, Farfel JM, et al. Predictors of in-hospital mortality among older patients. Clinics 2009; 64: 613-8.

9. Zhu Y, Liu Z, Wang Y, et al. C-reactive protein, frailty and overnight hospital admission in elderly individuals: a population-based study. Arch Gerontol Geriatr 2016; 64: 1-5.
10. Dentali F, Nigro O, Squizzato A, et al. Impact of neutrophils to lymphocytes ratio on major clinical outcomes in patients with acute coronary syndromes: a systematic review and meta-analysis of the literature. Int J Cardiol 2018; 266: 31-3.

11. Zhang Z, Xu X, Ni H, et al. Platelet indices are novel predictors of hospital mortality in intensive care unit patients. J Crit Care 2014; 29: 885.e1-6.

12. Oruç Ö, Morali T, Karakurt Z, et al. Hospitalization and mortality rates in patients with respiratory diseases in the very elderly population. J Gerontol Geriatr Res 2016; 5: 293.

13. Hosking MP, Warner MA, Lobdell CM, et al. Outcomes of surgery in patients 90 years of age and older. JAMA 1989; 261: 1909-15.

14. Pelavski AD, Lacasta $A$, Rochera $M I$, et al. Observational study of nonogenarians undergoing emergency, non-trauma surgery. Br J Anaesth 2011; 106: 189-93.

15. Ferrer A, Formiga F, Ruiz D, et al. Predictive items of functional decline and 2-year mortality in nonagenariansethe NonaSantfeliu study. Eur J Public Health 2008; 18: 406-9.

16. Andersen K, Nybo H, Gaist D, et al. Cognitive impairment and mortality among nonagenarians: the Danish 1905 cohort survey. Dement Geriatr Cogn Disord 2002; 13: 156-63.

17. Welte T, Torres A, Nathwani D. Clinical and economic burden of community-acquired pneumonia among adults in Europe. Thorax 2012; 67: 71-9.

18. Surkan MJ, Gibson W. Interventions to mobilize elderly patients and reduce length of hospital stay. Can J Cardiol 2018; 34: 881-8.

19. Sadeghia R, Banerjee T, Romine W. Early hospital mortality prediction using vital signals. Smart Health 2018; 9-10: 265-74.

20. Ball IM, Bagshaw SM, Burns KE, et al. A clinical prediction tool for hospital mortality in critically ill elderly patients. J Crit Care 2016; 35: 206-12.

21. Kim KI, Chin HJ, Kim KW, et al. Joint effect of C-reactive protein and high-density lipoprotein cholesterol in predicting shortterm mortality in older community-dwelling Korean population. J Am Geriatr Soc 2010; 58: 1201-2.

22. Poredoš P, Spirkoska A, Ježovnik MK. In patients with superficial vein thrombosis the inflammatory response is increased and related to the recanalization rate. Arch Med Sci 2019; 15: 393-401.

23. Dong $\mathrm{CH}$, Wang ZM, Chen SY. Neutrophil to lymphocyte ratio predict mortality and major adverse cardiac events in acute coronary syndrome: a systematic review and meta-analysis. Clin Biochem 2018; 52: 131-6.

24. Wang F, Wang L, Jiang TT, et al. Neutrophil-to-lymphocyte ratio is an independent predictor of 30-day mortality of intracerebral hemorrhage patients: a validation cohort study. Neurotox Res 2018; 34: 347-52.

25. Arques S, Pieri B, Biegle G, Roux E, Gelisse R, Jauffret B. Comparative value of B-type natriuretic peptide and serum albumin concentration in the prediction of in-hospital mortality in elderly patients admitted for acute severe heart failure. Ann Cardiol Angeiol 2009; 58: 279-83.

26. Arques S, Roux E, Stolidi P, Gelisse R, Ambrosi P. Usefulness of serum albumin and serum total cholesterol in the prediction of hospital death in older patients with severe, acute heart failure. Arch Cardiovasc Dis 2011; 104: 502-8.

27. Mene-Afejuku TO, Moisa EA, Akinlonu A, et al. The relevance of serum albumin among elderly patients with 
acute decompensated heart failure. J Geriatr Cardiol 2019; 16: 522-8

28. Ugajin M, Yamaki K, Iwamura N, Yagi T, Asano T. Blood urea nitrogen to serum albumin ratio independently predicts mortality and severity of community-acquired pneumonia. Int J General Med 2012; 5: 583-9.

29. Novello M, Mandarino FV, Di Saverio S, et al. Post-operative outcomes and predictors of mortality after colorectal cancer surgery in the very elderly patients. Heliyon 2019; 5: e02363.

30. Shahrokni A, Vishnevsky BM, Jang B, et al. Geriatric assessment, not ASA physical status, is associated with 6-month postoperative survival in patients with cancer aged $\geq 75$ years. J Natl Compr Canc Netw 2019; 17: 687-94.

31. Shahid J, Khan S, Marryam M, Amjad I. Frequency of mirror movements and comparison of hand function in spastic cerebral palsy children with and without mirror movements. J Pak Med Assoc 2019; 69: 1459-63.

32. Wang X, Fan X, Ji S, et al. Prognostic value of neutrophil to lymphocyte ratio in heart failure patients. Clin Chim Acta 2018; 485: 44-9.

33. Yodying H, Matsuda A, Miyashita M, et al. Prognostic significance of neutrophil-to-lymphocyte ratio and platelet-to-lymphocyte ratio in oncologic outcomes of esophageal cancer: a systematic review and meta-analysis. Ann Surg Oncol 2016; 23: 646-54. 